\title{
Cardiac abnormalities in young women with
}

\section{anorexia nervosa}

Giovanni de Simone, Luca Scalfi, Maurizio Galderisi, Aldo Celentano, Giuseppe Di Biase, Paolo Tammaro, Mario Garofalo, Gian Francesco Mureddu, Oreste de Divitiis, Franco Contaldo

Abstract
Objective-To identify the characteristics
of cardiac involvement in the self-induced
starvation phase of anorexia nervosa.
Methods-Doppler echocardiographic
indices of left ventricular geometry, func-
tion, and filling were examined in 21
white women (mean (SD) 22 (5) years)
with anorexia nervosa according to the
DSMII (Diagnostic and Statistical Manual of Mental Disorders) criteria, 19 women (23 (2) years) of normal weight, and 22 constitutionally thin women $(21$ (4) years) with body mass index $<20$.

Results-13 patients (62\%) had abnormalities of mitral valve motion compared with one normal weight woman and two thin women $(p<0.001) v$ both control groups). Left ventricular chamber dimension and mass were significantly less in women with anorexia nervosa than in either the women of normal weight or the thin women, even after standardisation for body size or after controlling for blood pressure. There were no substantial changes in left ventricular shape. Midwall shortening as a percentage of the values predicted from end systolic stress was significantly lower in the starving patients than in women of normal weight: when endocardial shortening was used as the index this difference was overestimated. The cardiac index was also significantly reduced in anorexia nervosa because of a low stroke index and heart rate. The total peripheral resistance was significantly higher in starving patients than in both control groups. The left atrial dimension was significantly smaller in anorexia than in the women of normal weight and the thin women, independently of body size. The transmitral flow velocity E/A ratio was significantly higher in anorexia than in both the control groups because of the reduction of peak velocity $A$. When data from all three groups were pooled the flow velocity $E / A$ ratio was inversely related to left atrial dimension $(r=-0.43, p<0.0001)$ and cardiac output $(r=-0.64, p<0.0001)$ independently of body size.

Conclusions-Anorexia nervosa caused demonstrable abnormalities of mitral valve motion and reduced left ventricular mass and filling associated with systolic dysfunction.

(Br Heart f 1994;71:287-292)
Sudden deaths in patients with anorexia nervosa ${ }^{1-4}$ suggest that cardiac involvement may contribute to the high mortality. ${ }^{2}$ There are reports of reduced left ventricular mass with normal cardiac function ${ }^{45}$ and of a high incidence of ventricular arrhythmias. ${ }^{4}$

A new non-linear method allows comparisons to be made of left ventricular mass among people groups with different body sizes. ${ }^{6}$ The method is based on allometric equations that generate exponents (called allometric signals) to express the power to which the measure of body size should be adjusted to derive a linear relation with left ventricular mass.

Little is known of haemodynamic function (that is, cardiac output, total peripheral resistance, left ventricular filling pattern) during starvation in anorexia nervosa.

Because of the possibility that refeeding may restore and/or preserve adequate pump function we studied left ventricular geometry and function in a group of young women in the starvation phase of anorexia nervosa.

\section{Patients and methods}

SUBJECTS

We studied 21 white women with selfinduced starvation (mean (SD) 22 (5) years) referred to the outpatient clinic of the Clinical Nutrition Unit of the Institute of Internal Medicine and Metabolic Diseases of Naples between 1990 and 1992. Two consultant psychiatrists based the diagnosis on the Diagnostic and Statistical Manual of Mental Disorders (DSMIII) criteria ${ }^{1}$ and a body mass index below 19 associated with a body weight that had been stable $( \pm 1 \mathrm{~kg})$ for at least three months before the study, according to clinical reports. None of the patients had clinical symptoms or signs of cardiovascular diseases. Patients and their families gave informed consent for the study.

We also studied 19 women (23 (2) years) of normal weight (body mass index $\geqslant 20$ and $<27 \cdot 3$ ) and 22 constitutionally thin women (21(4) years) with body mass index $<20$. Both controls in both groups were staff at the Institute of Internal Medicine and Metabolic Diseases or medical students at the "Federico II" University of Naples, who voluntarily underwent a complete echocardiographic study. None of the controls had a family history of hypertension.

Thin and anorexic women underwent a complete clinical examination by a physician and a psychiatrist and filled out a food 
questionnaire. Constitutionally thin women had had a history of leanness throughout their life and normal menstruation. Thin women and those of normal weight did not satisfy any of the DSM III criteria for the diagnosis of anorexia nervosa and had normal scores on the food questionnaire.

\section{PROCEDURES}

Cross sectional and $M$ mode echocardiographic examination was performed in the morning in a quiet warm room with the subjects in the left decubitus position. Transmitral and transaortic flow velocities were measured by Doppler echocardiography. Arterial blood pressure was measured at the first and fifth Korotkoff phases with a normal adult or paediatric arm cuff, according to the arm circumference, on a mercury manometer with the subject recumbent at the end of the echocardiographic study.

\section{ECHOCARDIOGRAPHY}

We examined the motion of the mitral valve leaflets in the parasternal long axis view, according to the criteria suggested by Pini et $a l,{ }^{7}$ to identify billowing or prolapse.

The $\mathrm{M}$ mode echocardiograms and Doppler signals were recorded on strip chart paper with the subject in a partial left decubitus position on a SIM7000 Echocardiograph (EsaOte, Florence, Italy) connected to a 3.5 or $5 \mathrm{MHz}$ split-annular transducer. $\mathrm{M}$ mode recordings were obtained with the ultrasound beam at or just below the tips of mitral valve leaflets in a parasternal short axis view. Strip chart tracings of all patients and controls were interpreted blindly by two observers. Septal and posterior wall thicknesses and left ventricular chamber dimensions were measured in at least three cardiac cycles according to the American Society of Echocardiography and the Penn conventions. ${ }^{89}$ Left atrial dimension was measured in the short axis view of the aortic root at the valve level as the maximum distance between the posterior left atrial wall and the centre of the external interface of the posterior aortic wall.

We used standard methods to calculate left ventricular mass and endocardial fractional shortening. ${ }^{1011}$ The relative diastolic mean wall thickness was calculated as the sum of the posterior wall and septal thicknesses divided by the diameter of the left ventricular internal chamber in diastole.

When the left ventricular structure is abnormal the mechanics of the midwall give a more appropriate assessment of left ventricular performance than the mechanics of the endocardium. ${ }^{12-14}$

Midwall fractional shortening was calculated as:

$(\mathrm{LVIDd}+\mathrm{PWTd} / 2+\mathrm{IVSTd} / 2)-(\mathrm{LVIDs}+\mathrm{PWTs} / 2+\mathrm{IVSTs} / 2)$ (LVIDd + PWTd/2 + IVSTd/2)

where $\mathrm{s}$ is systole and d diastole, LVID is left ventricular chamber dimension, PWT is posterior wall thickness, and IVST is septal thickness. ${ }^{14}$
We measured meridional end systolic stress (ESS) on the basis of cuff systolic blood pressure at the end of echocardiographic session according to a validated method ${ }^{15}$ and we examined the relation between endocardial and midwall fractional shortening and meridional end systolic stress. We predicted endocardial and midwall fractional shortening (FS) from the individual end systolic stress using regression equations based on a healthy reference population of 142 normotensive adults (endocardial FS $=92.22-31.64 \times$ $\log (\mathrm{ESS})$; midwall $\mathrm{FS}=39.98-10.32 \times$ $\log$ (ESS).${ }^{14}$ The ratio of observed to predicted endocardial or midwall fractional shortening was calculated as an index of left ventricular performance independent of the effect of myocardial afterload.

Stroke volume and cardiac output were measured by pulsed Doppler interrogation of the left ventricular outflow velocity in the long axis apical view and based on the aortic cross sectional area. ${ }^{16}$ Total peripheral resistance was calculated as 80 times the ratio of mean blood pressure to cardiac output. Left ventricular inflow velocity was measured in the apical four-chamber view under visual and auditory guidance to obtain the maximum peak velocity of transmitral flow in early diastole. ${ }^{1718}$ The rapid filling phase peak transmitral flow (velocity E) and the late diastolic filling phase peak transmitral flow (velocity A) were measured and the flow velocity $\mathrm{E} / \mathrm{A}$ ratio was derived.

\section{BODY SIZE INDEXING}

The left ventricular chamber dimension was indexed to the first power of height, whereas left ventricular mass was indexed to height to the $2 \cdot 7$ power, based on results of a recent multicentre study. ${ }^{6}$ Traditional standardisations for body surface were used for stroke volume and cardiac output, and are also reported for left ventricular mass to facilitate comparison with previous reports.

\section{STATISTICAL ANALYSIS}

Data were expressed as the mean (1SD). The $\chi^{2}$ statistic was used to evaluate the prevalence of mitral valve motion abnormalities. Oneway analysis of variance was used for intergroup comparisons with the step-down multiple stage post-hoc F-test for multiple comparisons. ${ }^{19}$ We also performed post-hoc tests on values adjusted for potential confounders by analysis of covariance. We used least-squares linear correlation analysis to study univariate relations between variables and partial correlation analysis to control for confounders. The null hypothesis was rejected at a two-tailed alpha value of $\leqslant 0 \cdot 05$.

\section{Results}

Table 1 shows the general characteristics of women in the three groups. Starving patients had lower heart rates and systolic and diastolic blood pressures than either normal-weight or thin women $(0.0001<\mathrm{p}<$ 0.05). 
Table 1 Characteristics (mean (1SD)) of young patients with anorexia nervosa compared with those of women of normal weight or constitutionally thin women

\begin{tabular}{lccc}
\hline Characteristic & $\begin{array}{c}\text { Anorexia nervosa } \\
(n=21)\end{array}$ & $\begin{array}{l}\text { Thin } \\
(n=22)\end{array}$ & $\begin{array}{l}\text { Normal weight } \\
(n=19)\end{array}$ \\
\hline Heart rate (beats/min) & $59(17)$ & $76(8) \ddagger$ & $73(10) \ddagger$ \\
Systolic BP (mm Hg) & $101(18)$ & $109(9)^{\star}$ & $118(7) \ddagger$ \\
Diastolic BP (mm Hg) & $66(13)$ & $72(7)^{\star}$ & $78(6) \ddagger$ \\
Body weight $(\mathrm{kg})$ & $38(6)$ & $52(5) \dagger$ & $61(6) \ddagger$ \\
Height $(\mathrm{m})$ & $1.59(0.05)$ & $1.66(0.07)$ & $1.63(0 \cdot 06)$ \\
Body mass index $\left(\mathrm{kg} / \mathrm{m}^{2}\right)$ & $15 \cdot 2(2 \cdot 0)$ & $19 \cdot 1(0.6)$ & $22.9(1.8) \ddagger$ \\
\hline
\end{tabular}

${ }^{\star} \mathrm{p}<0.05 ; \mathrm{tp}<0.01 ; \mathrm{fp}<0.0001 v$ starving patients.

$\mathrm{BP}$, blood pressure.

\section{PREVALENCE OF MITRAL VALVE PROLAPSE}

Thirteen $(62 \%)$ of 21 patients with anorexia nervosa showed mitral valve motion abnormalities (nine with billowing of one or both leaflets and four with prolapse) compared with one $(5.3 \%)$ of 19 normal weight women $(\mathrm{p}<0.0008)$ or two $(9.1 \%)$ of 22 constitutionally thin women $(p<0.001)$. We did not find Doppler evidence of an important mitral regurgitation jet in patients or controls.

\section{CARDIAC ANATOMY}

The left ventricular chamber dimension was smaller in anorexia nervosa than in the control groups (both $\mathrm{p}<0.0001$ ) (table 2 ). These differences remained after indexing for height (table 2) or controlling for body weight, height, and heart rate by analysis of covariance (adjusted mean values were 4.69 and $4.46 \mathrm{~cm}$ for women of normal weight and thin women $(\mathrm{p}<0.03)$ and $3.93 \mathrm{~cm}$ for starving patients (both $\mathrm{p}<0.0001$ ).

Left ventricular mass was indeed lower in the starving patients than in either the women of normal weight or thin women (both

Table 2 Measures of left ventricular anatomy (mean (1SD)) in young patients with anorexia nervosa compared with women of normal weight or constitutionally thin women (mean (1SD))

\begin{tabular}{|c|c|c|c|}
\hline Measure & $\begin{array}{l}\text { Anorexia nervosa } \\
(n=21)\end{array}$ & $\begin{array}{l}\text { Thin } \\
(n=22)\end{array}$ & $\begin{array}{l}\text { Normal weight } \\
(n=19)\end{array}$ \\
\hline $\begin{array}{l}\text { LV dimension }(\mathrm{cm}) \\
\text { LV dimension } / \mathrm{height}(\mathrm{cm} / \mathrm{m}) \\
\text { LV mass }(\mathrm{g}) \\
\text { LV mass } / \mathrm{BSA}\left(\mathrm{g} / \mathrm{m}^{2}\right) \\
\text { LV mass } / \mathrm{height}\left(\mathrm{g} / \mathrm{m}^{2 \cdot 7}\right) \\
\text { Relative wall thickness } \oint\end{array}$ & $\begin{array}{c}3.96(0.33) \\
2.49(0.20) \\
73.3(22.3) \\
54.9(16.8) \\
21.1(6.5) \\
0.36(0.06)\end{array}$ & $\begin{array}{c}4.41(0.36) \dagger \ddagger \\
2.66(0.23)^{\star} \ddagger \\
103.0(23.8) \dagger \ddagger \\
66.9(15 \cdot 1)^{\star} \ddagger \\
26.5(6.3)^{\star} \\
0.35(0.05)\end{array}$ & $\begin{array}{c}4 \cdot 72(0 \cdot 35) \dagger \ddagger \\
2 \cdot 90(0 \cdot 24) \dagger \ddagger \\
124 \cdot 0(22 \cdot 8) \dagger \ddagger \\
75 \cdot 2(12 \cdot 6) \dagger \ddagger \\
33 \cdot 2(6 \cdot 3) \dagger \\
0.34(0.05)\end{array}$ \\
\hline
\end{tabular}

${ }^{\star} \mathrm{p}<0.01$ and $\mathrm{tp}<0.0001 v$ starving patients. $\neq \mathrm{p}<0.05$ to $\mathrm{p}<0.001$ between control groups. After controlling for body weight and height the relative wall thickness was higher in starving patients than in either women of normal weight or thin women (see text).

LV, left ventricular; BSA, body surface area.

Table 3 Left ventricular systolic function in young patients with anorexia nervosa, in women of normal weight, and constitutionally thin women (mean (1SD))

\begin{tabular}{|c|c|c|c|}
\hline Index & $\begin{array}{l}\text { Anorexia nervosa } \\
(n=21)\end{array}$ & $\begin{array}{l}\text { Thin } \\
(n=22)\end{array}$ & $\begin{array}{l}\text { Normal weight } \\
(n=19)\end{array}$ \\
\hline $\begin{array}{l}\text { End systolic stress } \times 10^{3}\left(\mathrm{dyn} / \mathrm{cm}^{2}\right) \\
\text { Endocardial }(\mathrm{e}) \text { shortening }(\%) \\
\text { Midwall }(\mathrm{m}) \text { shortening }(\%) \\
\% \text { Predicted m-shortening }(\%) \\
\% \text { Predicted e-shortening }(\%) \\
\text { Cardiac output }(1 / \mathrm{min}) \\
\text { Cardiac index }\left(1 / \mathrm{min} / \mathrm{m}^{2}\right) \\
\text { Stroke volume }(\mathrm{ml} / \mathrm{beat}) \\
\text { Stroke index }\left(\mathrm{ml} / \mathrm{beat} / \mathrm{m}^{2}\right) \\
\text { TP resistance }\left(\text { dyn } \cdot \mathrm{s} \cdot \mathrm{cm}^{-5}\right)\end{array}$ & $\begin{array}{l}59(20) \\
32 \cdot 6(5 \cdot 6) \\
20 \cdot 1(3 \cdot 6) \\
91 \cdot 4(15 \cdot 1) \\
88 \cdot 4(11 \cdot 4) \\
2 \cdot 69(0 \cdot 90) \\
2 \cdot 01(0 \cdot 64) \\
46 \cdot 2(10 \cdot 3) \\
29 \cdot 1(6 \cdot 5) \\
2791(1133)\end{array}$ & $\begin{array}{l}60(14) \\
34 \cdot 3(8 \cdot 1) \\
21 \cdot 1(3 \cdot 0) \\
97 \cdot 3(13 \cdot 5) \\
95 \cdot 7(10 \cdot 9) \star \S \\
4 \cdot 39(1 \cdot 00) \pm \S \\
2 \cdot 87(0 \cdot 73) \pm \S \\
58 \cdot 4(15 \cdot 4)+5 \\
\left.35 \cdot 3(9 \cdot 5)^{\star}\right\rfloor \\
1636(333)^{\star}\end{array}$ & $\begin{array}{l}62(16) \\
35 \cdot 1(5 \cdot 8) \\
22 \cdot 7(3 \cdot 5) \\
104 \cdot 8(13 \cdot 8) \star \\
103 \cdot 1(10 \cdot 3) \ddagger \\
5 \cdot 57(1 \cdot 02) \ddagger \\
3 \cdot 40(0 \cdot 70) \ddagger \\
77 \cdot 6(16 \cdot 3) \ddagger \\
47 \cdot 7(10 \cdot 7) \ddagger \\
1527(319) \ddagger\end{array}$ \\
\hline
\end{tabular}

$\star_{\mathrm{p}}<0.05 ; \mathrm{tp}<0.01 ; \neq \mathrm{p}<0.001 v$ starving patients. $\mathrm{lp}<0.05-\mathrm{p}<0.001$ for comparisons between control groups.

TP, total peripheral. $\mathrm{p}<0.0001$ ); thin women had smaller left ventricular masses than women of normal weight $(p<0.005)$. These differences were confirmed after indexing for height ${ }^{2 \cdot 7}$ (table 2) and were slightly reduced after controlling for body weight and height by analysis of covariance (adjusted mean values of left ventricular mass were $107 \mathrm{~g}$ and $100 \mathrm{~g}$ for women of normal weight and thin women and $92 \mathrm{~g}$ for starving patients $(\mathrm{p}<0.05 v$ thin and $\mathrm{p}<0.01 v$ normal weight). In the pooled group left ventricular mass was more closely related to stroke volume $(r=0.70, p<0.0001)$ than to systolic blood pressure ( $r=0.36$, $\mathrm{p}<0.005)$ and was inversely related to flow velocity $E / A$ ratio $(r=-0.39, p<0.002)$.

Left ventricular relative wall thickness was not statistically altered in patients with anorexia nervosa. After controlling for body weight and height by analysis of covariance, however, the mean value of relative wall thickness was significantly higher in starving patients than in either normal-weight or thin controls $(p<0.0001$ and $p<0.02$, respectively; adjusted mean values were 0.30 and 0.35 for normal-weight and thin women ( $p<$ 0.01 ), 0.39 for starving patients).

Because differences in left ventricular mass may depend on difference in blood pressure among groups, left ventricular mass/height ${ }^{2 \cdot 7}$ was also compared after controlling for systolic blood pressure by analysis of covariance. There was no substantial change in the results (adjusted mean values were $33 \mathrm{~g} / \mathrm{m}^{2 \cdot 7}$ for normal-weight, $26 \mathrm{~g} / \mathrm{m}^{2 \cdot 7}$ for thin women $(\mathrm{p}<0.002)$, and $21 \mathrm{~g} / \mathrm{m}^{2.7}$ for starving patients (both $\mathrm{p}<0.0001$ ).

\section{LEFT VENTRICULAR MECHANICS AND PUMP FUNCTION}

End systolic stress was similar in all the groups. There were no significant differences in endocardial and midwall fractional shortening among groups (table 3). However, midwall fractional shortening as a percentage of that predicted from end systolic stress was significantly lower in starving patients than in normal-weight controls $(p<0.02)$. This difference was considerably overestimated when it was estimated from the less physiologically appropriate measurement of endocardial fractional shortening expressed as a percentage of predicted $(\mathrm{p}<0.0004 v$ normal-weight women and $\mathrm{p}<0.04 v$ thin women).

Cardiac output and cardiac index were lower in starving patients than in either normal-weight or thin controls (comparison with both control groups $p<0.0005$, table 3 ), because of reduced stroke volume and heart rate. Though blood pressure was quite low (table 1) total peripheral resistance was very high in patients with anorexia nervosa (comparison with both control groups $\mathrm{p}<0.0001$, table 3 ).

LEFT VENTRICULAR FILLING PATTERN

Consistent with the left ventricular chamber dimension, the left atrial dimension was lower in patients with anorexia nervosa $(2.55(0.33)$ $\mathrm{cm})$ than in either women of normal weight $(3.09(0.31) \mathrm{cm})$ or in thin women $(2.87$ 
Table 4 Left ventricular filling pattern in young patients with anorexia nervosa compared with women of normal weight and constitutionally thin women (mean (1SD))

\begin{tabular}{llll}
\hline Index & $\begin{array}{l}\text { Anorexia nervosa } \\
(n=21)\end{array}$ & $\begin{array}{l}\text { Thin } \\
(n=22)\end{array}$ & $\begin{array}{l}\text { Normal weight } \\
(n=19)\end{array}$ \\
\hline Peak E Velocity $(\mathrm{m} / \mathrm{s})$ & $0.84(0 \cdot 24)$ & $0.90(0 \cdot 16)$ & $0.90(0 \cdot 14)$ \\
Peak A Velocity $(\mathrm{m} / \mathrm{s})$ & $0.43(0 \cdot 09)$ & $0.52(0 \cdot 15)^{\star}$ & $0.56(0.09) \ddagger$ \\
Peak E/A ratio & $1.96(0 \cdot 21)$ & $1.51(0.19) \dagger$ & $1.52(0.25) \dagger$ \\
\hline
\end{tabular}

${ }^{\star} \mathrm{p}<0.05 ; \dagger$ and $\ddagger \mathrm{p}<0.005$ or $<0.01 v$ starving patients.

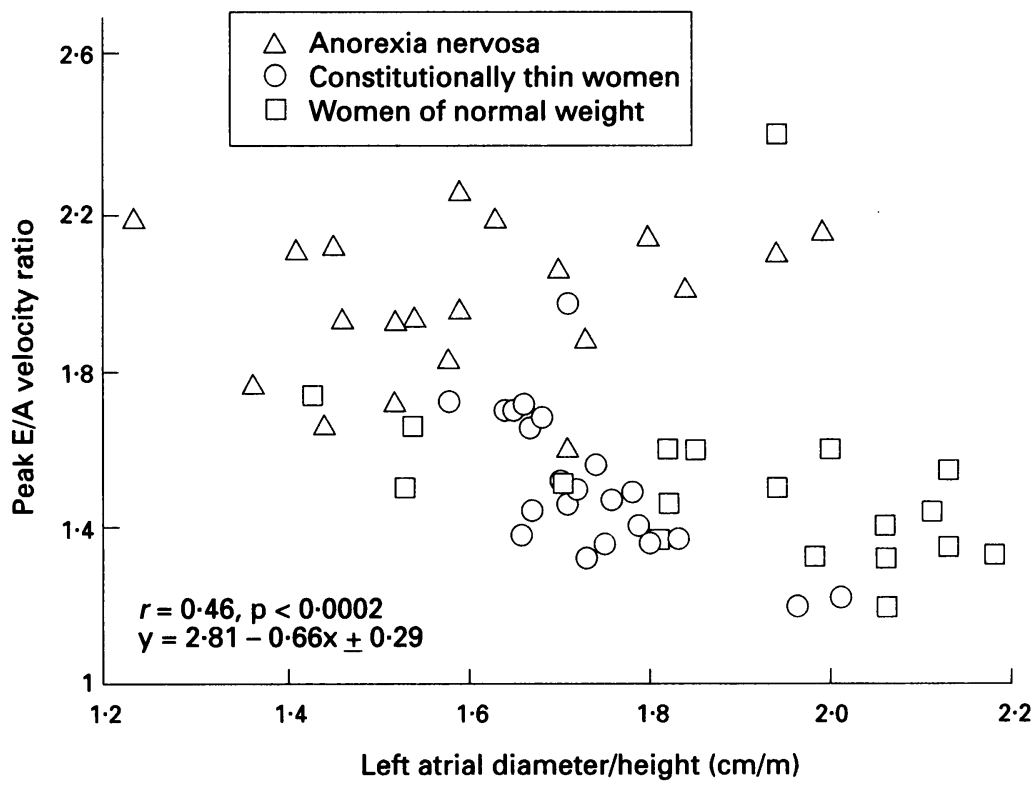

Figure 1 Relation of peak E/A transmitral velocity ratio to left atrial dimension normalised for body height in women with anorexia nervosa, constitutionally thin women, and women of normal weight. The coefficient of correlation, two tailed $p$ value, equation of regression, and standard error of the estimate are shown.

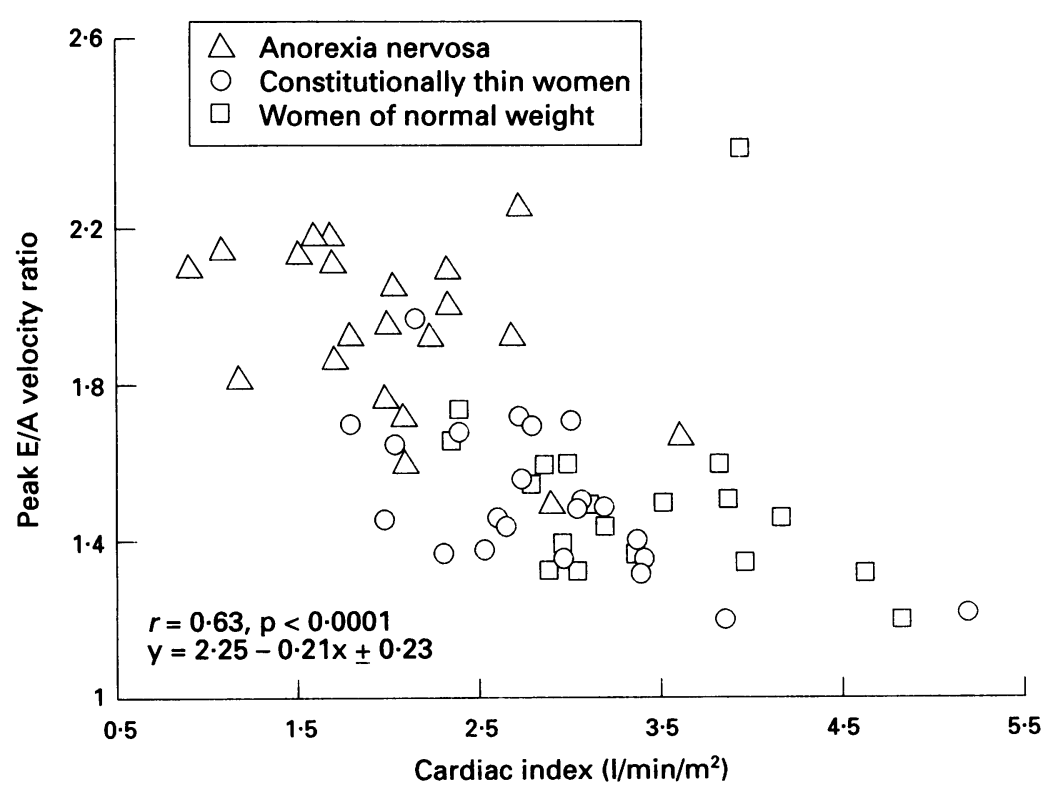

Figure 2 Relation of peak E/A transmitral velocity ratio to cardiac index $\left(\mathrm{l} / \mathrm{m}^{2}\right)$ in Figure 2 Relation of peak E/A transmitral velocity ratio to cardiac index $\left(\mathrm{l} / \mathrm{m}^{2}\right)$ in
women with anorexia nervosa, constitutionally thin women, and women of normal weight. women with anorexia nervosa, constitutionally thin women, and women of normal weight. of the estimate are shown.
$(0 \cdot 23) \mathrm{cm})$ (comparison with both control groups $\mathrm{p}<0.0001)$. Differences remained significant after indexing for height $(1.61(0 \cdot 19) v$ $1.74(0.20) \mathrm{cm}$ in thin women $(\mathrm{p}<.0 .02)$ and $1.90(0.22) \mathrm{cm}$ in women of normal weight $(\mathrm{p}<0.0001)$.

The transmitral peak E velocity was similar in patients with anorexia nervosa and in the control groups. In contrast, starving patients had a smaller peak A velocity than normalweight and thin women (comparisons with both control groups $p<0.05$, table 4 ), which increased the E/A flow velocity ratio (comparison with both control groups $\mathrm{p}<0.005)$. In the pooled group the E/A flow velocity ratio was inversely related to left atrial dimension $(r=-0.43, p<0.0004)$, left atrial dimension index (fig $1, p<0.0002)$, cardiac output $(r=$ $-0.64, \mathrm{p}<0.0001$ ), cardiac index (fig $2, \mathrm{p}<$ 0.0001 ), left ventricular chamber dimension $(\mathrm{r}=-0.33, \mathrm{p}<0.009$, left ventricular chamber dimension/height $(r=-0.37, p<0.003)$, stroke volume $(\mathrm{r}=-0.37, \mathrm{p}<0.003)$, stroke index $(r=-0.38, p<0.003)$, heart rate $(\mathrm{r}=-0.64, \mathrm{p}<0.0001)$, and body weight $(\mathrm{r}=-0.44, \mathrm{p}<0.0003)$. The differences in the E/A flow velocity ratio between starving patients and the control groups remained significant after we controlled for heart rate by analysis of covariance (adjusted mean values 1.55 for normal-weight, 1.56 for thin women, and 1.87 for starving patients (comparison with both control groups $p<0.0001)$. After we controlled for the effect of body weight by partial correlation analysis the relations remained significant for cardiac index (partial $r=-0.54, p<0.0001$ ), left atrial dimension/height (partial $\mathrm{r}=-0.34, \mathrm{p}<0.007$ ), and heart rate (partial $\mathrm{r}=-0.56, \mathrm{p}<$ 0.0001 ).

The relation of left ventricular filling pattern to systolic performance was also investigated. The E/A flow velocity ratio was inversely related to indices of left ventricular performance $(r=-0.39, p<0.002$ for endocardial shortening; $r=-0.32, p<0.02$ for midwall shortening; $r=-0.38, p<0.003$ for observed/predicted endocardial shortening; $r=-0.29, p<0.03$ for observed/predicted midwall shortening). These relations remained significant after we controlled for body weight by partial correlation analysis (all $\mathrm{p} \leqslant 0.05)$.

\section{Discussion}

Mortality in anorexia nervosa is high because of suicide and as consequence of uncontrollable protein deprivation..$^{20}$ As in other forms of malnutrition, the heart can be involved. ${ }^{21-23}$

In earlier studies a reduction in left ventricular mass was an easily detectable characteristic of the heart involvement in anorexia nervosa ${ }^{4} 5$ but without evidence of left ventricular dysfunction. We extended these observations by studying midwall performance and loading conditions in the left ventricle during the starvation phase of anorexia nervosa. We found a distinctive pattern of left ventricular mechanics. 


\section{LEFT VENTRICULAR GEOMETRY}

Because of the complex relation between left ventricular mass and measures of body size we compared women with anorexia nervosa with women with either a normal body size (as in the study of St John Sutton et l $^{5}$ or thin constitution to examine the direct effect of body size. In addition we used a non-linear approach to index left ventricular mass to height. This approach was based on an allometric equation derived from 611 normalweight normotensive subjects in a multicentre study. ${ }^{6}$ We could, therefore, investigate whether or not left ventricular geometric abnormalities were present and were characteristic of the self-induced starvation phase of anorexia nervosa.

As in previous studies, ${ }^{45}$ our analysis confirmed that left ventricular mass was reduced in anorexia nervosa in the phase of selfinduced starvation. The considerable reduction was only slightly lessened after adjusting for both body weight and height. This procedure may be especially convenient in patients in whom body weight is almost completely determined by lean body mass. ${ }^{24}$

Even after we controlled for blood pressure left ventricular mass remained low in patients with anorexia nervosa. St John Sutton et al ${ }^{5}$ speculated that early changes in myocardial afterload induced a downregulation of growth of the left ventricle in these patients. Our results suggest that in starving patients preload too is reduced. Thus in our patients left ventricular mass was mainly reduced because of a decrease in left ventricular chamber dimension. As in hypertensive patients, ${ }^{25}$ left ventricular mass was proportional to stroke volume and inversely related to the $E / A$ flow velocity ratio: both relations suggest a considerable reduction of preload in our patients, which would influence left ventricular mass and lead to concentric remodelling of the cavity. This pattern resembles that described by Heymsfield et al in cachectic patients. $^{26}$

LEFT VENTRICULAR FILLING PATTERN

We found that left ventricular filling was severely impaired in patients with anorexia nervosa. In addition to the increased E/A flow velocity ratio, the reduction in left atrial and ventricular dimensions and stroke volume and the inverse relations between the E/A ratio and stroke volume and cardiac output confirm that preload was much reduced in these patients,-exactly the opposite pattern to that seen in obese individuals. ${ }^{27}$ Almost all left ventricular filling in patients with anorexia nervosa occurred in the early diastolic phase. Others showed that patients in the starvation phase of anorexia nervosa are severely dehydrated. ${ }^{28}{ }^{29}$ Compensatory activation of reninangiotensin system could increase peripheral resistance, despite the reduced blood pressure and the possible reduction of circulating noradrenaline concentrations already reported. ${ }^{4}$

LEFT VENTRICULAR MECHANIC

Left ventricular performance assessed by both the endocardial and midwall approaches was somewhat depressed in anorexia nervosa in the starvation phase, compared with normalweight women and constitutionally thin women. In earlier studies left ventricular performance was reported to be normal in anorexia nervosa. ${ }^{5}$ Different selection criteria in terms of both severity and phase of the disease and differences in the methods may account for these inconsistencies. We assessed left ventricular performance in terms of the difference in left ventricular chamber or midwall shortening from the value predicted for a given level of end systolic wall stress..$^{14031}$ This method provides a measure of left ventricular function that is independent of the influence of myocardial afterload. Although end systolic stress-shortening relations are principally affected by left ventricular contractility, chronic deviations in preload can influence the degree of ventricular shortening. ${ }^{32}$ Evidence of mild left ventricular dysfunction in the starvation phase of anorexia nervosa is therefore not surprising. It resembles the findings in other types of malnutrition. ${ }^{21-23}$ Though in our evaluation of left ventricular performance we controlled for the effect of afterload (end systolic stress) we could not discriminate between the effects of preload and myocardial contractility. Nonetheless, indirect evidence from earlier studies, which suggested reduced circulating volume, ${ }^{28}$ histological abnormalities of the myocardium, ${ }^{22}$ and autonomic dysfunction, ${ }^{4}$ implies that left ventricular dysfunction in anorexia nervosa is probably caused by both inappropriate left ventricular filling and reduced myocardial contractility. An earlier study suggests that impaired left ventricular filling and the consequent reduction of left ventricular chamber dimension possibly account for the high prevalence of abnormalities of mitral valve motion seen in our patients with anorexia nervosa in the starvation phase. ${ }^{33}$

The identification of silent left ventricular dysfunction in patients with anorexia nervosa in the starvation phase may help us to devise refeeding programmes to prevent heart failure, a complication that often develops during clinical refeeding. ${ }^{3435}$ The haemodynamic pattern that we found in our study suggests that when there is contractile dysfunction an abrupt increase in preload, which often develops during refeeding, might precipitate heart failure. This dysfunction together with the electrolyte abnormalities that occur during refeeding (that is, hypokalaemia and hypophosphatataemia), ${ }^{35}$ could lead to sudden death in these patients.

Distinctive cardiac abnormalities were found in starvation caused by anorexia nervosa. There were abnormalities of mitral valve motion without significant mitral regurgitation, reduced left ventricular mass, impaired left ventricular filling, and left ventricular systolic dysfunction. Controlled studies should be performed to show the effect of refeeding on each abnormality and to determine whether any of these abnormalities can be corrected and to evaluate the extent of the recovery. 
This study was supported in part by grant (MURST 60\%, 1991) from the Ministero dell Universita' e della ricerca.

We thank the dieticians (Mia Silvestro and Anna Rita Caldara) and the psychiatrists (Dr Oreste Bellini and Dr Giancardo Di Pietro) who cooperated in this study.

1 Williams JBW. Diagnostic and statistical manual of mental disorders (DSM III). 3rd ed. Washington DC: American disorders (DSM III). 3rd ed. Was

2 Isner JM, Roberts WC, Heymsfield SB, Yager J. Anorexia nervosa and sudden death. Ann Intern Med 1985;102: 49-52.

3 Thurston J, Marks P. Electrocardiographic abnormalities in patients with anorexia nervosa. Br Heart $\mathcal{f} 1974 ; 36$ : $719-23$.

4 Gottdiener JS, Gross HA, Henry WL, Borer JS, Ebert MH. Effects of self-induced starvation on cardiac size and function in anorexia nervosa. Circulation 1978;58: 425-33.

5 St John Sutton MG, Plappert T, Crosby L, Douglas P, Mullen J, Reichek N. Effects of reduced left ventricular mass on chamber architecture, load and function: a mass on chamber architecture, load and function: a
study of anorexia nervosa. Circulation 1985;72: 991-1000.

6 de Simone G, Daniels SR, Devereux RB, Meyer RA, Roman MJ, de Divitiis O, Alderman MH. Left ventricular mass and body size in normotensive children and adults: Assessment of allometric relations and of the impact of overweight. $\mathcal{F} \mathrm{Am}$ Coll Cardiol 1992;20: 1251-60.

7 Pini R, Greppi B, Kramer-Fox R, Roman MJ, Devereux RB: Mitral valve dimensions and motion and familial transmission of mitral valve prolapse with or without mitral leaflet billowing. $f \mathrm{Am}$ Coll Cardiol 1988;12: mitral leafle

8 Sahn DJ, DeMaria A, Kisslo J, Weyman A. The Committee on M-mode Standardization of the American Society of Echocardiography: Recommendations regarding quantitation in M-mode echocardiography. Results of a survey of echocardiographic measurements. Circulation 1978;58:1072-83.

9 Devereux RB, Reichek N. Echocardiographic determination of left ventricular mass in man. Anatomic validation tion of left ventricular mass in man. Anatomic

10 Devereux RB. Evaluation of cardiac structure and function by echocardiography and other noninvasive techniques. In: Laragh JH, Brenner BM, eds. Hypertension: pathophysiology, diagnosis, treatment. New York: Raven Press: 1990:1479-92.

11 de Simone G, Di Lorenzo L, Constantino G, Moccia D, Buonissimo S, de Divitiis O: Supernormal contractility in primary hypertension without left ventricular hypertrophy. Hypertension 1988;11:457-63.

12 Shimuzu G, Zile MR, Blaustein AS, Gaasch WH. Left ventricular chamber filling and midwall fiber lengthening in patients with left ventricular hypertrophy: overestimation of fiber velocities by conventional midwall measurements. Circulation 1985;71:266-72.

13 Shimuzu G, Hirota Y, Kita Y, Kawamura K, Saito T, Gaasch WH. Left ventricular midwall mechanics in systemic arterial hypertension. Myocardial function is depressed in pressure-overload hypertrophy. Circulation 1991;83:1676-84.

14 de Simone G, Devereux RB, Roman MJ, Alderman MH, Laragh $\mathrm{JH}$. Assessment of left ventricular function by mid-wall fractional shortening in human hypertension [abstr]. Circulation 1992;86(suppl I):727.

15 Reichek N, Wilson J, St John Sutton M, Plappert TA, Goldberg S, Hirshfeld JW: Noninvasive determination of left ventricular end-systolic stress. Validation of the method and initial application. Circulation 1982;65: 99-109.

16 Dubin J, Wallerson DC, Cody RJ, Devereux RB. Comparative accuracy of Doppler echocardiographic methods for clinical stroke volume determination. $A m$ Heart f 1990;120:116-23.

17 Galderisi M, Celentano A, Tammaro P, Mureddu GF, Garofalo M, de Simone G, de Divitiis O. Ambulatory blood pressure monitoring in offspring of hypertensive patients: relation to left ventricular structure and funcpatients: relation to left ventricular s
tion. Am $\mathcal{f}$ Hypertens 1993;6:114-20.

18 Nishimura RA, Abel MD, Hatle LK, Tajik AJ. Assessment of diastolic function of the heart: background and current applications of Doppler echocardiography. Part II. Clinical studies. Mayo Clin Proc 1989;64:181-204.

19 Einot I, Gabriel KR: A study of the powers of several methods of multiple comparisons. F Am Stat Ass 1975; 70:574-83.

20 Biller BMK, Saxe V, Herzog DB, Rosenthal DI, Holzman $S$, Klibanski A. Mechanisms of osteoporosis in adult and adolescent women with anorexia nervosa. $\exists$ Clin adolescent women with anorex
Endocrinol Metab 1989;68:548-54.

21 Keys A, Brozek J, Henschel A, Mickelson O, Taylor HL. The biology of human starvation, vol II. Minneapolis: University of Minnesota Press. 1950:968.

22 Piza J, Troper L, Cespedes R, Miller JH, Berenson GS. Myocardial lesions and heart failure in infantile malnutrition. Am f Trop Med Hyg 1971;20:343-55.

23 Keys A, Henschel A, Taylor HI. The size and function of the human heart at rest in semi-starvation and in the subsequent rehabilitation. Am $\mathcal{F}$ Physiol 1947;50:153-69.

24 Mazess RB, Barden HS, Ohlrich ES: Skeletal and body composition effects of anorexia nervosa. Am 7 Clin Nutr 1990;52:438-41.

25 Ganau A, Devereux RB, Pickering TG, Roman MJ, Schnall PL, Santucci S, Spitzer MC, Laragh JH. Relation of left ventricular hemodynamic load and contractile performance to left ventricular mass in hypertension. Circulation 1990;81:25-36.

26 Heymsfield SB, Bethel RA, Ansley JD, Gibbs DM, Felner JM, Nutter DO. Cardiac abnormalities in cachectic patients before and during nutritional repletion. $\mathrm{Am}$ peart $\mathcal{f} 1978 ; 95: 584-94$.

27 de Divitiis O, Fazio S, Petitto M, Maddalena G, Contaldo F, Mancini M: Obesity and cardiac function. Circulation F, Mancini M: O

28 Herzog DB, Copeland PM: Eating disorders. $N$ Engl f Med 1985;313:295-303.

29 Lucas AR, Huse DM. Behavioral disorders affecting food intake: anorexia nervosa and bulimia. In: Shils ME, Young VR, eds. Modern nutrition in health and disease. Philadelphia: Lea \& Febiger, 1988:1450-7.

30 Ross JJ. Applications and limitations of end-systolic measures of left ventricular performance. Fed Proc 1984; 43:1418-22.

31 Lutas EM, Devereux RB, Reis G, et al. Increased cardiac performance in mild essential hypertension: Left ventricperformance in mild essential hypertension: L
ular mechanics. Hypertension 1985;7:979-88.

32 Mirsky I, Aoyuagi T, Crocker VM, Fujii AM. Preload dependence of fiber shortening rate in conscious dogs with left ventricular hypertrophy. $f \mathrm{Am}$ Coll Cardio 1990;15:890-9.

33 Meyers DG, Starke H, Pearson PH, Wilken MK. Mitral valve prolapse in anorexia nervosa. Ann Intern Med 1986;105:384-5.

34 Brozek J, Chapman CB, Keys A. Drastic food restriction: effect on cardiovascular dynamics in normotensive and effect on cardiovascular dynamics in normotensive and hypertensive

35 Solomon SM, Kirby DF. The refeeding syndrome: a review. $\mathcal{F}$ Parent Ent Nutr 1990;14:90-7. 